\title{
Depression Subscale of the Hospital Anxiety and Depression Scale applied preoperatively in spinal surgery
}

\author{
Subescala de Depressão da Escala Hospitalar de Depressão e Ansiedade no pré-operatório \\ de coluna vertebral
}

\begin{abstract}
Asdrubal Falavigna ${ }^{1}$, Orlando Righesso ${ }^{2}$, Alisson Roberto Teles ${ }^{3}$, Natália Baseggio ${ }^{4}$, Maíra Cristina Velho Leonardo Gilmone Ruschel4, Fabiola Abruzzi4, Pedro Guarise da Silva ${ }^{4}$
\end{abstract}

\begin{abstract}
Objective: To evaluate the accuracy of the Depression Subscale of Hospital Anxiety and Depression Scale (HADS-D) in spine surgery, comparing it to Beck Depression Inventory (BDI). Methods: In a cross-sectional study, the HADS-D and the BDI were applied to patients undergoing spine surgery for lumbar $(n=139)$ or cervical spondylosis $(n=17)$. Spearman correlation tests for HADS-D and BDI were applied. The internal consistency of HADS-D was estimated by Cronbach's alpha coefficient. Results: According to the BDI, the prevalence of depression was of $28.8 \%(n=45)$. The Spearman $r$ coefficient between HADS-D and BDI was $0.714(p<0.001)$. Cronbach's alpha for HADS-D was 0.795 , The area of the ROC curve was 0.845 . Using a cutoff for HADS-D $\geq 10$, there was a sensitivity of $71.1 \%$, specificity of $95.4 \%$, and positive likelihood-ratio of 15.78. Conclusions: HADS-D showed a strong correlation with BDI and good reliability. HADS-D is a good alternative for screening depression and assessing its severity.
\end{abstract}

Key words: spine surgery, depression, Hospital Anxiety and Depression Scale, Beck Depression Inventory.

RESUMO

Objetivo: Avaliar a acurácia da Subescala de Depressão da Escala Hospitalar de Depressão e Ansiedade (HADS-D) em cirurgia da coluna, comparando-a com o Inventário de Depressão de Beck (BDI). Métodos: Estudo transversal, no qual a HADS-D e o BDI foram aplicados em pacientes submetidos à cirurgia da coluna vertebral por espondilose lombar $(n=139)$ ou cervical $(n=17)$. Teste de correlação de Spearman foi aplicado entre HADS-D e BDI. A consistência interna da HADS-D foi estimada pelo coeficiente alfa de Cronbach. Resultados: De acordo com o BDI, a prevalência de depressão foi de 28,8\% ( $n=45)$. 0 coeficiente r de Spearman entre HADS-D e BDI foi de 0,714 ( $p<0,001)$. Alpha de Cronbach para o HADS-D foi de 0,795. A área da curva ROC foi de 0,845. Usando um corte para HADS-D $\geq 10$, houve sensibilidade de 71,1\%, especificidade de 95,4\% e razão de verossimilhança positiva de 15,78. Conclusões: HADS-D apresentou forte correlação com o BDI e boa confiabilidade. A HADS-D é uma boa alternativa para a triagem de depressão e verificação da gravidade dos sintomas.

Palavras-Chave: cirurgia da coluna, depressão, Escala Hospitalar de Ansiedade e Depressão, Inventário de Depressão de Beck.

Depression and anxiety are mood disorders that are commonly related to chronic illnesses. The overall frequency in hospitalized patients has an index of variation between 20 and $60 \%^{1-3}$, and they are not recognized in one third of patients ${ }^{4}$. Their frequency can be higher in patients without mood disorders presenting symptoms caused by physical illness or preoperative anxiety, which range from 11 to $80 \%$ in adults ${ }^{5}$. This variation is related to the sociodemographic characteristics of the population studied, type of disease, degree of involvement, chronicity, and variability of the methodological definitions used in the studies, such as the cutoff point, the search tools, and the case definition. The literature offers different scales for the assessment of anxiety and depression, such as Beck Depression Inventory (BDI), Hospital

\footnotetext{
Laboratório de Estudos Clínicos e Modelos Básicos de Patologias Raquimedulares da Universidade de Caxias do Sul (LPR-UCS), Caxias do Sul RS, Brazil.

${ }^{1}$ Professor of Neurology and Neurosurgery, University of Caxias do Sul; Coordinator of Medical Faculty of Universidade de Caxias do Sul; Coordinator of the Multidisciplinary Student League of Neurology and Neurosurgery of the University of Caxias do Sul (LAMNN-UCS), Caxias do Sul RS, Brazil;

${ }^{2}$ Medical Doctor, Orthopedist, Bento Gonçalves RS, Brazil;

${ }^{3}$ Medical Doctor, Resident of Neurosurgery, Hospital São José - Santa Casa de Porto Alegre, Porto Alegre RS, Brazil;

${ }^{4}$ Medical students, University of Caxias do Sul, Caxias do Sul RS, Brazil;

${ }^{5}$ Medical Doctor, Resident of Neurosurgery, Hospital Beneficiência Portuguesa de Porto Alegre, Porto Alegre RS, Brazil. Correspondence: Asdrubal Falavigna; Coordinator of the Medical Faculty of the University of Caxias do Sul; Rua General Arcy da Rocha Nóbrega 401 / 602 ; 95040-290 Caxias do Sul RS - Brasil; E-mail: asdrubalmd@gmail.com

Conflict of interest: There is no conflict of interest to declare.

Received 14 July 2011; Received in final form 18 October 2011; Accepted 25 October 2011
} 
Anxiety and Depression Scale (HADS), Hamilton Anxiety Scale, and State Trait Anxiety Inventory I and II $^{6-9}$.

Investigating depression in the preoperative period of spinal surgery is important because of its effect on the outcomes of surgery. According to Mannion et al. ${ }^{10}$, the psychosocial variables, measured by the Zung depression scale and Fear Avoidance and Believe Scale (FAB), predict 20\% variance of disability, function and general well-being in patients. Trief, Ploutz-Snyder and Fredrickso showed that presurgical emotional status is a significant predictor of pain and function outcomes in spinal fusion surgery ${ }^{11}$. In patients who have chronic low back pain and undergo lumbar fusion, psychological and emotional stress negatively affect the postoperative outcome ${ }^{12}$. Also, regarding patients' expectations and satisfaction after surgery, the depressed ones tended to have lower expectations and, consequently, lower satisfaction ${ }^{13}$.

To our knowledge, there are no studies assessing the screening accuracy of the Depression Subscale of the Hospital Anxiety and Depression Scale (HADS-D) in the diagnosis of depression in patients undergoing spine surgery. The objective of this study was to evaluate this instrument in a population comprised of patients with spondylosis, who were selected for spine surgery comparing it to BDI, which was considered the golden-standard questionnaire for the diagnosis of depression ${ }^{3}$. The importance of this study, besides evaluating their equivalence in depression diagnosis, is that time spent filling out the HADS-D questionnaire was at least $50 \%$ lower than the BDI.

\section{METHODS}

\section{Design and sample}

In this cross-sectional study, after signing a letter of consent, participants were asked to complete a structured, closed-ended questionnaire in the period before surgery. The inclusion criteria were patients aged 18 or over and indication of surgery for spinal degenerative disorder. Indications for surgery were axial and radicular pain refractory to clinical treatment associated or not with progressive neurological deficits. There were 83 patients with disc herniation, 22 with spondylolisthesis, 46 with degenerative spinal stenosis and 5 with degenerative scoliosis. All patients underwent decompression with or without fusion for treatment of lumbar (139) or cervical $(\mathrm{n}=17)$ spondylosis. Five patients of the sample had a previous spine surgery $(3.2 \%)$ and 28 were in work compensation (17.9\%). The mean age of the sample was 50.6 yearsold $( \pm 12.6)$ and $52.6 \%$ were female. The study was submitted to the Ethics and Research Committee of the University of Caxias do Sul (UCS) and it was approved. All the selected patients answered the BDI and HADS-D in the preoperative period, without any interaction of medical or research staff, in the outpatient clinic.

\section{Instrument}

BDI is a self-report questionnaire widely used to screen the presence of depression through its 21 items of symptoms and attitudes related to the presence and intensity of signs of this mood disorder. Each question is scored on a four-point scale ranging from no impairment (0) to severe impairment (3), the maximum score being 63. The cutoff of depression diagnostic using BDI in this survey was set at $\geq 15$, with this cutoff, the test has a $90 \%$ sensitivity, $99 \%$ specificity, positive predictive value of 0.82 , negative predictive value of 0.99 , and an overall diagnostic value of $99 \%{ }^{14}$. The Brazilian-Portuguese language translation and validation were performed in 1996, by Gorestein and Andrade ${ }^{15}$.

The HADS was designed to provide a practical tool to identify and quantify the two most common forms of psychological disorders, depression, and anxiety ${ }^{16}$. It was used initially in patients who had been in clinical psychiatric hospitals, and then extended to evaluate a non-hospitalized patient with some type of disease or individuals without disease ${ }^{17-20}$. HADS does not consider vegetative symptoms associated with depression and anxiety $^{21-22}$, and it also does not allow interferences of somatic symptoms in the assessment. HADS consists of a 14-item selfreport questionnaire incorporating seven questions for anxiety and seven others for depression ${ }^{8}$. The seven questions about depressive symptoms comprise the Depression Subscale of Hospital Anxiety and Depression Scale. Each item is scored 0 to 3 , and a total score of 8 or greater on one or both subscales indicates the presence of a depressive or anxiety disorder. HADS was translated and validated for the Brazilian-Portuguese language, by Botega ${ }^{23}$. HADS has been used as a screening questionnaire in patients before the spine surgery ${ }^{24}$.

\section{Statistical analysis}

Statistical analysis was performed with SPSS $^{\circledR} 16$ for Windows (SPSS Inc., Chicago, IL, USA). The categorical variables were presented as proportions, and the age as mean and standard deviation. Statistical significance was considered if $\mathrm{p} \leq 0.05$. The internal consistency was examined using the Cronbach's alpha, whose results above 0.7 were considered adequate. The internal consistency reflects the dimensions that items of a questionnaire measure for the same phenomenon, thus using this analysis to evaluate its reliability. The Spearman correlation test was peformed to evaluate the correlation between HADS-D and BDI. The Receiver Operating Characteristic (ROC) curve was used to show the sensitivity (or true-positive rate) and one-specificity (or false-positive rate). The cutoff for depression diagnosis in this survey was set as $\geq 15$ points for BDI.

\section{RESULTS}

All 156 patients answered the questionnaires in the preoperative period without any difficulties. The time spent to 
fill out the BDI questionnaire was from 10 to 15 minutes and for HADS-D, from three to five minutes.

The mean BDI score was $11.05( \pm 7.33)$, and the mean of HADS-D was $6.85( \pm 2.90)$. Depression was observed in 45 patients $(28.8 \%)$, according to BDI cutoff. Spearman's r coefficient between HADS-D and BDI was 0.714 ( $\mathrm{p}<0.001)$, as seen in Fig 1.

The analyses of internal consistency for each item of depression subscale are shown in Table. The Cronbach's alpha value for HADS-D was 0.795. The item "I have lost interest in my appearance" had the lowest correlation coefficient to total HAD-D scale (Table).

The ROC curve area was 0.845 (0.781-0.908) as shown in Fig 2. The best accuracy of HADS-D was observed with cutoff of 10 points in the subscale. Using a cutoff value for HADS$\mathrm{D} \geq 10$, we observed a $71.1 \%$ sensibility, a $95.4 \%$ specificity, a $72.2 \%$ positive predictive value, and a $76.8 \%$ negative predictive value, and a positive likelihood-ratio of $15.78 \%$.

\section{DISCUSSION}

In patients, who had chronic low back pain and underwent lumbar fusion, psychological and emotional stress negatively affects postoperative outcome ${ }^{12}$. Also, regarding the patients' expectations and satisfactions after surgery, depressed patients tended to have lower expectations and, consequently, lower satisfaction ${ }^{13}$. Therefore, it is very important for spine surgeons to verify the presence of depression in the preoperative period for degenerative spinal disorders ${ }^{3}$.

One of the most used screening instruments to detect depression is BDI. This instrument is considered to have good accuracy for detecting depression ${ }^{14}$. Another available questionnaire for evaluating mood disorders is the HADS; it is composed by 14 items, 7 of them compound the HADS-D. In this study, the mean time to answer the BDI was two to three times longer than to answer the HADS-D.

We evaluated the subscale HADS-D as a screening tool to detect depressive symptoms in the preoperative period of spine surgery. The accuracy of HADS-D was evaluated using the BDI scores as diagnostic of depression. The internal consistency of HADS-D was measured with Cronbach's alpha

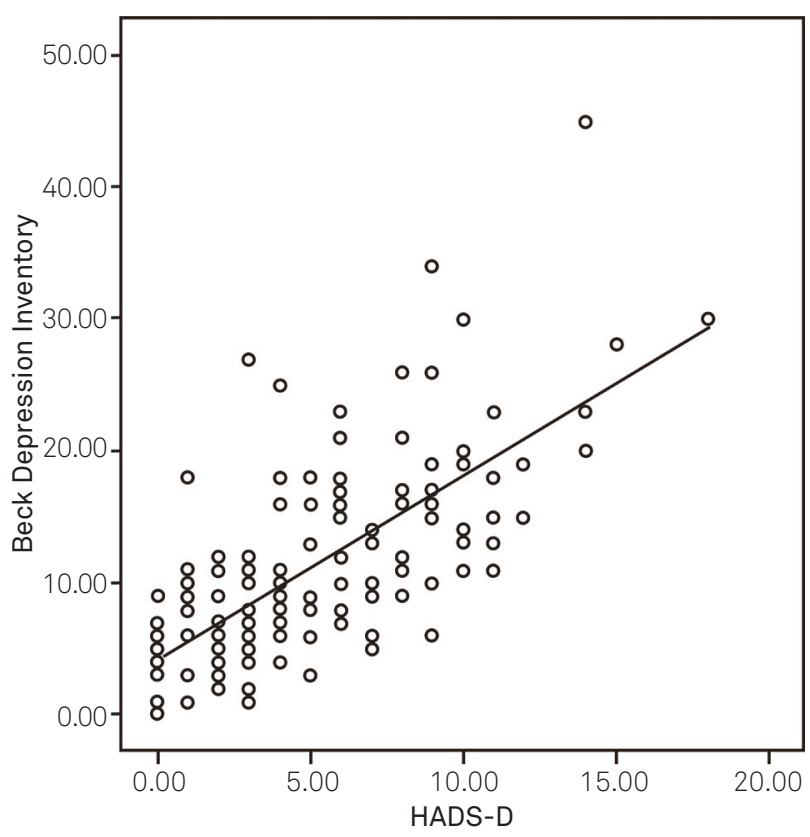

Fig 1. Correlation between Depression Subscale of Hospital Anxiety and Depression Scale (HADS-D) and Beck Depression Inventory.

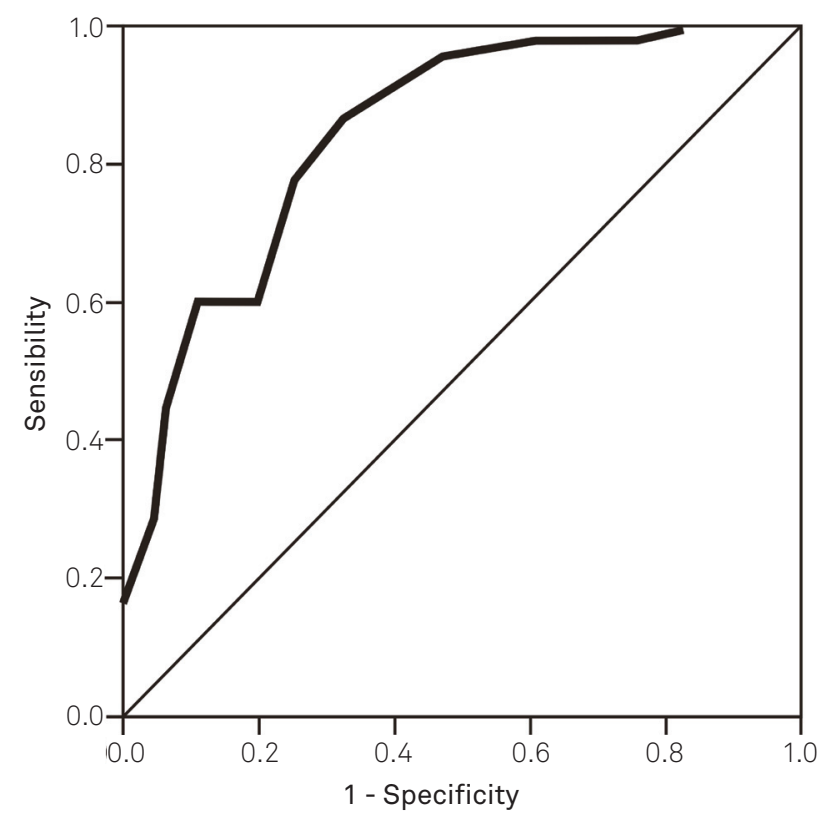

Fig 2. ROC curve for sensibility and specificity of Depression Subscale of Hospital Anxiety and Depression.

Table. Inter-scale correlation and Cronbach's $\alpha$ value for total HADS-D.

\begin{tabular}{lcc} 
HADS-D Items & HADS-D & $\begin{array}{c}\text { Cronbach's } \alpha \text { (if item delected) } \\
\text { or the total HADS-D }\end{array}$ \\
\hline 2 - I still enjoy the things I used to enjoy & 0.702 & 0.760 \\
4 - I can laugh and see the funny side of things & 0.725 & 0.755 \\
- I feel cheerful & 0.730 & 0.755 \\
8 - I feel as if I am slowed down & 0.650 & 0.779 \\
10 - I have lost interest in my appearance & 0.569 & 0.786 \\
12 - I look forward with enjoyment to things & 0.663 & 0.770 \\
14 - I can enjoy a good book or radio or TV program & 0.675 & 0.776 \\
\hline
\end{tabular}

Cronbach's alpha=0.795. HADS-D: Hospital Anxiety and Depression Scale. 
coefficient, as for screening tools ${ }^{22}$. The internal consistency of HADS-D was 0.795, which demonstrated good internal consistency according to Nunally ${ }^{25}$. In the review carried out by Bjelland and Dahlb, the internal consistency of HADS (total scale) ranged from 0.67 to 0.90 , which reassures and strengthens the cohesion of the items of this instrument ${ }^{26}$. The authors suggest that the value found in the internal consistency was high probably because of the small number of items in the scale and in the sample ${ }^{26}$. The internal consistency of our study was higher than the 0.77 found in the studies of Botega ${ }^{23}$, which estimated the prevalence of mood disorders in patients in a general adult ward. The Cronbach's alpha found in our study was lower than the 0.83 observed by Marcolino, Mathias and Filho $(0.83)^{21}$, who studied the validity and reliability of the HADS test in patients preoperatively to general surgery.

The HADS-D scale was compared with BDI, considered golden-standard for the screening depression ${ }^{21}$. There was a strong correlation between HADS-D and BDI, measured by the $r$ Spearman coefficient, which was consistent with the studies of Bjelland and Dahlb, proving that the HADS-D can be used separately from the anxiety scale as we tested in this study $^{26}$. Sensibility and specificity of the HADS-D test were, respectively, 71.1 and $95.4 \%$, surpassing the value published in the literature and showing the capacity of the scale to identify depression ${ }^{23,26-27}$. The ROC curve found in this study was 0.845, which was similar to those in the literature. Olsson, Mykletun and Dahl described a sensibility and specificity of 0.80 and 0.88 , respectively, and a ROC curve area under $0.93^{28}$.

The tools applied by doctors usually differentiate anxiety and depression ${ }^{29-30}$. However, it is hard to distinguish depression and anxiety using scales of self-assessment due to the low discrimination rate between them ${ }^{29-30}$. To the best of our knowledge, this was the first study to test the HADS-D separately to identify depression in patients with degenerative spinal disorders. The results of our study demonstrated the good consistency and reliability of this instrument as a screening tool in these patients.

In conclusion, HADS-D presented a strong correlation with BDI and a good internal consistency. This scale can be used separately from the anxiety subscale without compromising its reliability. The HADS-D is a good alternative for screening depression and its severity during the preoperative period of spine surgery, as this subscale is easier and faster for the patient to answer than the BDI.

\section{References}

1. Mayou R, Hawton K. Psychiatric disorder in the general hospital. Br J Psychiatry 1986;149:172-190.

2. Saravay SM. Psychiatric interventions in the medically ill. Outcome and effectiveness research. Psychiatr Clin North Am 1996;19:467-480.

3. Falavigna A, Righesso O, Teles AR. Clinical and functional evaluation in preoperative period of degenerative disease spine surgery. Coluna/Columna 2009;8:245-253.

4. Querido A. Forecast and follow-up an investigation into the clinical, social, and mental factors determining the results of hospital treatment. Br J Prev Soc Med 1959;13:33-49.

5. Maranets I, Kain ZN. Preoperative anxiety and intraoperative anesthetic requirements. Anesth Analg 1999;89:1346-1351.

6. Hamilton M. Development of a rating scale for primary depressive illness. Br J Soc Clin Psychol 1967;6:278-296.

7. Beck AT, Ward CH, Mendelson M, Mock J, Erbaugh J. An inventory for measuring depression. Arch Gen Psychiatry 1961;4:561-571.

8. Zigmond AS, Snaith RP. The hospital anxiety and depression scale. Acta Psychiatr Scand 1983;67:361-370.

9. Johnson DT, Spielberger CD. The effects of relaxation training and the passage of time on measures of state- and trait-anxiety. J Clin Psychol 1968;24:20-23.

10. MannionAF,ElferingA,StaerkleR,etal.Predictorsofmultidimensional outcome after spinal surgery. Eur Spine J 2007;16:777-786.

11. Trief PM, Ploutz-Snyder R, Fredrickson BE. Emotional health predicts pain and function after fusion: a prospective multicenter study. Spine 2006;31:823-830.

12. Derby R, Lettice JJ, Kula TA, Lee SH, Seo KS, Kim BJ. Single-level lumbar fusion in chronic discogenic low-back pain: psychological and emotional status as a predictor of outcome measured using the 36-item Short Form. J Neurosurg Spine 2005;3:255-261.

13. Toyone T, Tanaka T, Kato D, Kaneyama R, Otsuka M. Patients' expectations and satisfaction in lumbar spine surgery. Spine 2005;30:2689-2694.

14. Lasa L, Ayuso-Mateos JL, Vazquez-Barquero JL, Diez-Manrique FJ, Dowrick CF. The use of the Beck Depression Inventory to screen for depression in the general population: a preliminary analysis. J Affect Disord 2000;57:261-265.

15. Gorenstein C, Andrade L. Validation of a Portuguese version of the Beck Depression Inventory and the State-Trait Anxiety Inventory in Brazilian subjects. Braz J Med Biol Res 1996;29:453-457.

16. Herrmann C. International experiences with the Hospital Anxiety and Depression Scale--a review of validation data and clinical results. J Psychosom Res 1997;42:17-41.

17. Kliszcz J, Nowicka-Sauer K, Trzeciak B, Sadowska A. The level of anxiety, depression and aggression in nurses and their life and job satisfaction. Med Pr 2004;55:461-468.

18. Brandberg Y, Sandelin K, Erikson S, Jurell G, Liljegren A, Lindblom A. Psychological reactions, quality of life, and body image after bilateral prophylactic mastectomy in women at high risk for breast cancer: a prospective 1-year follow-up study. J Clin Oncol 2008;26:3943-3949.

19. Andrews B, Hejdenberg J, Wilding J. Student anxiety and depression: comparison of questionnaire and interview assessments. J Affect Disord 2006;95:29-34.

20. Vage V, Solhaug JH, Viste A, Bergsholm P, Wahl AK. Anxiety, depression and health-related quality of life after jejunoileal bypass: a 25-year follow-up study of 20 female patients. Obes Surg 2003;13:706-713.

21. Marcolino JAM, Mathias LAST, Filho LP. Hospital Anxiety and Depression Scale: a study on the validation of the criteria and reliability on preoperative patients. Rev Bras Anestesiologia 2007;57:52-62.

22. Marcolino JAM, Suzuki FM, Alli LAC, Gozzani JL, Mathias LADST. Measurement of anxiety and depression in preoperative patients. comparative study. Rev Bras Anestesiologia 2007;57:157-166. 
23. Botega NJ. Mood disorders among medical in-patients: a validation study of the hospital anxiety and depression scale (HAD). Rev Saúde Pública 1995;29:55-63.

24. Guilfoyle MR, Seeley H, Laing RJ. The Short Form 36 health survey in spine disease--validation against condition-specific measures. $\mathrm{Br} J$ Neurosurg 2009;23:401-405.

25. Nunnally J. Psychometric theory. New York: McGraw Hill; 1978.

26. Bjelland I, Dahlb AA. The validity of the Hospital Anxiety and Depression Scale An updated literature review. J Psychosom Res 2002;52:69-77.

27. Whelan-Goodinson R, Ponsford J, Schonberger M. Validity of the
Hospital Anxiety and Depression Scale to assess depression and anxiety following traumatic brain injury as compared with the Structured Clinical Interview for DSM-IV. J Affect Disord 2009;114:94-102.

28. Olsson I, Mykletun A, Dahl AA. The Hospital Anxiety and Depression Rating Scale: a cross-sectional study of psychometrics and case finding abilities in general practice. BMC Psychiatry 2005;5:46-50.

29. Mendels J, Weinstein N, Cochrane C. The relationship between depression and anxiety. Arch Gen Psychiatry 1972;27:649-653.

30. Lewis G. Observer bias in the assessment of anxiety and depression. Soc Psychiatry Psychiatr Epidemiol 1991;26:265-272. 